\title{
Principles for designing a computer application specific to explosion risk management in explosive deposits
}

\author{
Florin Ionel Burdea ${ }^{1 *}$, and Monica Crinela Burdea $^{2}$ \\ ${ }^{1}$ ITM Hunedoara, Muncii Alley, no.2, Deva, Hunedoara, Romania \\ ${ }^{2}$ University of Petroşani, Management and Industrial Engineering Department, University Street, \\ no.20, 332006, Petrosani, Hunedoara, Romania
}

\begin{abstract}
Industrial explosive storage sites are considered to be areas of major risk to industrial, public and occupational safety and security, due to the possibility of major accidents, due to the nature of the explosive substances and due to the serious consequences of an explosion.on these sites. The explosion risk assessment for explosives depots requires an analysis of all possible occurrences of the initiating events that could lead to a potential explosion, followed by an analysis of security measures, all of which are quantified by the development of accident trees and sequences. for each possible trigger. This paper presents the principles of designing a specialized computer application in the field of explosion risk management at explosives depots for civilian use. This application allows to ensure the necessary premises for the elaboration, in objective and specific conditions, of the necessary documents for these types of technical infrastructures, from their design phase and the quantification of the degree of damage on the analyzed locations but also in the areas that are located.
\end{abstract}

\section{Introduction}

Industrial sites where explosives are stored or produced are always took into consideration as major risk areas for industrial, public, and occupational safety and security. Risk areas due to the possibility of major accidents, both due to seriousness of the consequences that a possible explosion phenomenon produced on these sites can generate. The major accident prevention policy must be compatible with the general policy in the field of activity of the organization and with the policies of other branches of management, such as quality or environmental management. This policy must have the principle of preventive action and the concept of sustainable development so that economically feasible technical safety measures prevent and limit the consequences of the use of hazardous substances on public health and the environment.

According to the definition, "major accident" means "an adverse phenomenon, such as major emissions, fire or explosion". These accidents resulting from uncontrolled events during the operation of an objective covered by the presence of the Seveso Directives and

${ }^{*}$ Corresponding author: ionelburdea@yahoo.com 
which poses a serious danger to human health and / or the environment, immediately or late, inside or outside the target, involving one or more hazardous substances" [1], [2].

For the prevention at source of industrial accidents, it is particularly important that this prevention policy must be more than a simple statement of intent of the management at the highest level (top management). The company must ensure that the policy is applied and that a high level of protection is ensured by implementing all necessary measures (not only technical, but also those aimed at the organizational structure and management of the company) to achieve this goal [3], [4].

Safety professionals are increasingly interested in quantitative risk assessment and understand that no occupational activity, including those involving explosives, is risk-free [5], [3], [6].

The simple quantitative risk assessment does not eliminate the risk of events caused by activities involving explosives. Thus being necessary tools to ensure the application of a management system as efficient as possible, which ensures both the assessment of the level of risk in the activities carried out and the measures, which must be taken to eliminate, reduce both the risks and the consequences of possible events [7], [6].

As a result, for sites where various activities involving explosive substances are carried out, both the assessment of the security of the systems and the conduct of activities on those sites and the proper management of risks are mandatory objectives for industrial units and competent authorities in the field.

The quantified explosion risk assessment for explosives depots requires a complete analysis of all possible occurrences of the initiating events that could lead to a potential explosion. An explosion materialized either by detonation or deflagration or a combination of these two types of explosive phenomena, followed by an analysis of the security measures that could be adopted, by installing technical security barriers or by applying other measures of an organizational or other nature, so as to aim at preventing any possibility of the initiating event already identified. Risk assessment is a structured procedure for qualitative and / or quantitative assessment of the level of risk generated by hazard sources identified in installations [8], [9]. The purpose of the risk assessment is to provide the information needed to make a decision.

It is increasingly recommended that risk identification, assessment and control processes be carried out especially proactively rather than reactively. The implementation of technical means of protection can increase costs, if these means are implemented after the completion of the design of a storage site or after its construction In general, changes made in the design phase are less costly and more efficient than those made later, which fully justifies the start of the risk analysis and assessment process from this stage.

\section{Development of accident scenarios starting from the triggering factor}

The direct causes (initiating events) that may underlie the explosion-type events on the sites where operations with explosives are carried out, identified based on the literature and following the analysis of events in Romania, were organized in the form of a logical scheme Master Logic Diagram (MLD) type, as shown in Figure 2.1 [5]. 


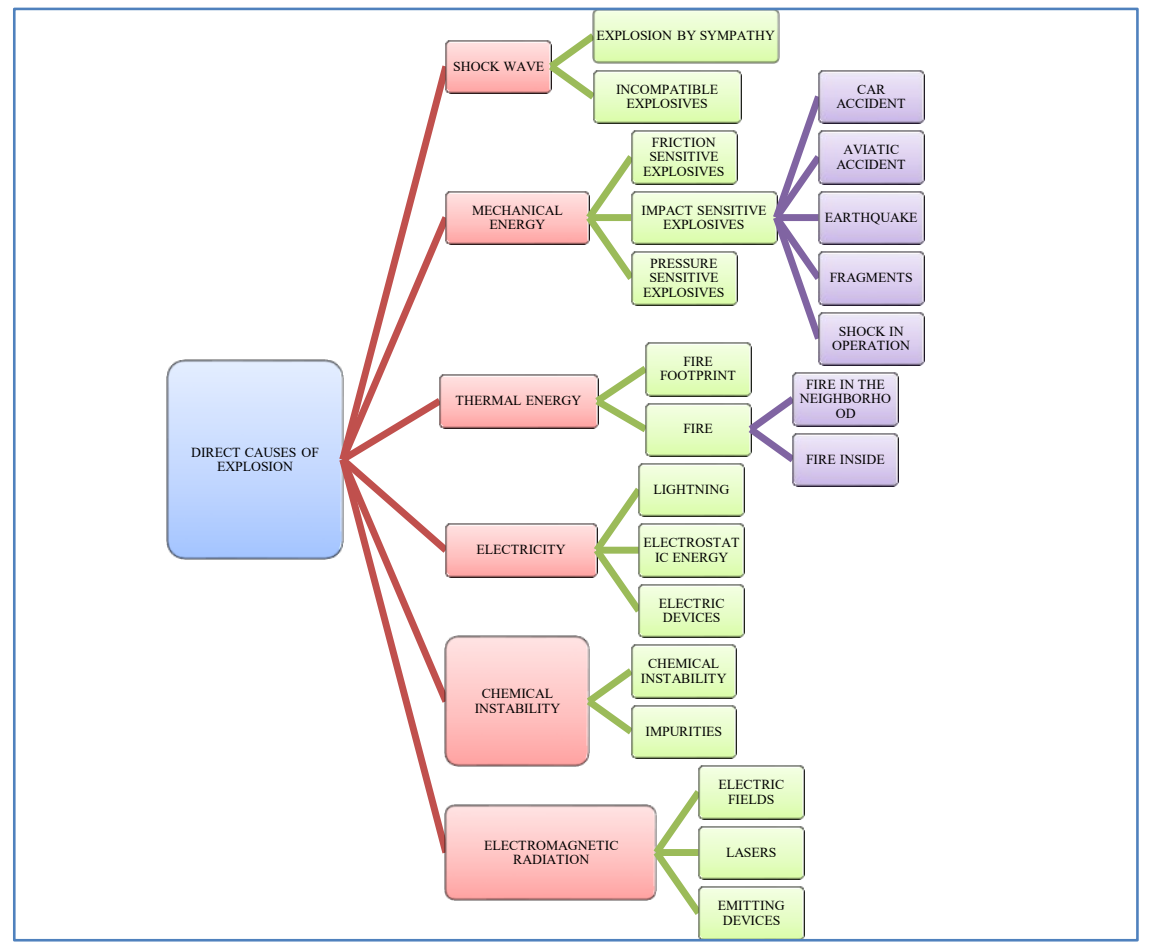

Fig. 2.1 - MLD Diagram Causes of initiation of the explosion

From the research of the specialized literature and of the events produced in the past on the Romanian territory but also in other countries, several initiating events (triggering factors) have been identified that can evolve towards a direct cause of an explosion, as presented in Table 2.1.

Table 2.1 - Triggers identified

\begin{tabular}{|l|l|}
\hline Symbol & Description \\
\hline D1 & Incompatible explosives \\
\hline D2 & Car accident inside the warehouse \\
\hline D3 & Plane crash \\
\hline D4 & Earthquake \\
\hline D5 & Explosions in the neighborhood \\
\hline D6 & Impact sensitive explosives \\
\hline D7 & Friction sensitive explosives \\
\hline D8 & Atmospheric surges, lightning \\
\hline D9 & Sparks from malfunction of electrical equipment \\
\hline D10 & Sparks due to static electricity \\
\hline D11 & Chemically unstable explosives \\
\hline D12 & Impurities in the composition of explosives \\
\hline D13 & Electro-explosive devices \\
\hline D14 & Outdoor fires \\
\hline D15 & Indoor fires \\
\hline
\end{tabular}

For each of these triggers, several safety measures have been identified that can be adopted and implemented both to prevent the explosion and to limit the effects. These safety measures may be of a technical nature. represented by the installation of some 
technical protection and / or organizational barriers, represented by the implementation of some procedures and good practices, as they are presented in Table 2.2.

Table 2.2 - Inventory table of safety measures

\begin{tabular}{|c|c|c|}
\hline \multicolumn{3}{|c|}{ Safety measures } \\
\hline Symbol & Name of the measure & Description \\
\hline \multicolumn{3}{|c|}{ TECHNICAL MEASURES } \\
\hline T1 & $\begin{array}{l}\text { Constructive protection of the warehouse (building) - type of } \\
\text { warehouse }\end{array}$ & \\
\hline $\mathbf{T 2}$ & Arrangement of separate rooms for storage of incompatible explosives & \\
\hline T3 & Protective barriers between storage rooms & \\
\hline T4 & Shock-resistant equipment & \\
\hline T5 & $\begin{array}{l}\text { Racks and shelves arranged so that the impact energy is less than the } \\
\text { ignition energy }\end{array}$ & \\
\hline T6 & $\begin{array}{l}\text { Storage of explosives on shelves racks in packing boxes so as to avoid } \\
\text { friction and / or frictional energy less than the ignition energy }\end{array}$ & \\
\hline T7 & Lightning protection & \\
\hline T8 & Earthing of electrical equipment and protection of personnel & \\
\hline T9 & Explosive distribution flow adapted to reduce storage time & \\
\hline T10 & $\begin{array}{l}\text { Prevention of contact with impurities - Maintenance and cleaning of } \\
\text { storage spaces }\end{array}$ & \\
\hline T11 & Explosion-proof encapsulation of electrical equipment & \\
\hline T12 & Disposal of sources & \\
\hline T13 & Dispersion currents with energy lower than ignition energy & \\
\hline T14 & Elimination of laser radiation sources & \\
\hline T15 & Elimination of radio sources & \\
\hline T16 & Elimination of mobile telephone radiation sources & \\
\hline T17 & Outdoor and indoor fire detectors & \\
\hline T18 & Trained operators for fire detection and operational intervention & \\
\hline T19 & $\begin{array}{l}\text { Water tanks, wells water or connection of the storage to the water } \\
\text { network, fire hydrants }\end{array}$ & \\
\hline T20 & Equipped with high pressure pumps, diesel or electric pumps & \\
\hline T21 & Equipped with sprinklers, sprinklers & \\
\hline T22 & ADR authorized vehicles, fire protected & \\
\hline T23 & Fire extinguishers & \\
\hline T24 & Barricades, fences, earth waves for protection of the deposit & \\
\hline \multicolumn{3}{|c|}{ MĂSURI ORGANIZATORICE } \\
\hline $\mathbf{O 1}$ & Procedures for avoiding the joint storage of incompatible explosives & \\
\hline $\mathbf{O 2}$ & Procedures for labeling explosives by compatibility groups & \\
\hline $\mathbf{O 3}$ & $\begin{array}{l}\text { Procedures for licensing and licensing of vehicles and drivers for the } \\
\text { transport of dangerous goods (ADR) }\end{array}$ & \\
\hline O4 & $\begin{array}{l}\text { Procedures for limiting the speed of vehicles transporting explosives } \\
\text { inside the site }\end{array}$ & \\
\hline $\mathbf{0 5}$ & Procedures for clearing of vegetation inside the warehouse & \\
\hline O6 & $\begin{array}{l}\text { Procedures for operating / maintenance procedures to avoid shocks } \\
\text { caused by impact }\end{array}$ & \\
\hline $\mathbf{O 7}$ & $\begin{array}{l}\text { Procedures for handling, loading / unloading and transport to avoid } \\
\text { shocks caused by impact }\end{array}$ & \\
\hline O8 & Procedures for selecting equipment to reduce impact, shock absorption & \\
\hline O9 & $\begin{array}{l}\text { Procedures for handling, transport and storage for prevention and } \\
\text { reduction of contact and friction between stored explosives }\end{array}$ & \\
\hline $\mathbf{O 1 0}$ & Verification of equipment according to ATEX procedures & \\
\hline
\end{tabular}




\begin{tabular}{|l|l|l|}
\hline O11 & Procedures for performing explosives stability tests & \\
\hline O12 & Procedures for adapting explosives storage flow to shorten storage times & \\
\hline $\mathbf{O 1 3}$ & Quality control & \\
\hline $\mathbf{O 1 4}$ & Production control & \\
\hline $\mathbf{O 1 5}$ & Procedures for space maintenance and cleaning & \\
\hline $\mathbf{O 1 6}$ & Procedures and checks for measuring electromagnetic fields & \\
\hline $\mathbf{O 1 7}$ & Procedures for preventing laser radiation & \\
\hline
\end{tabular}

For each of the triggering factors analyzed, the corresponding accident sequences and event trees are elaborated, in Figure 2.2 [5,10]. and in Table 2.3 are presented the tree of events and the accident sequences corresponding to the trigger factor D1- Incompatible explosives

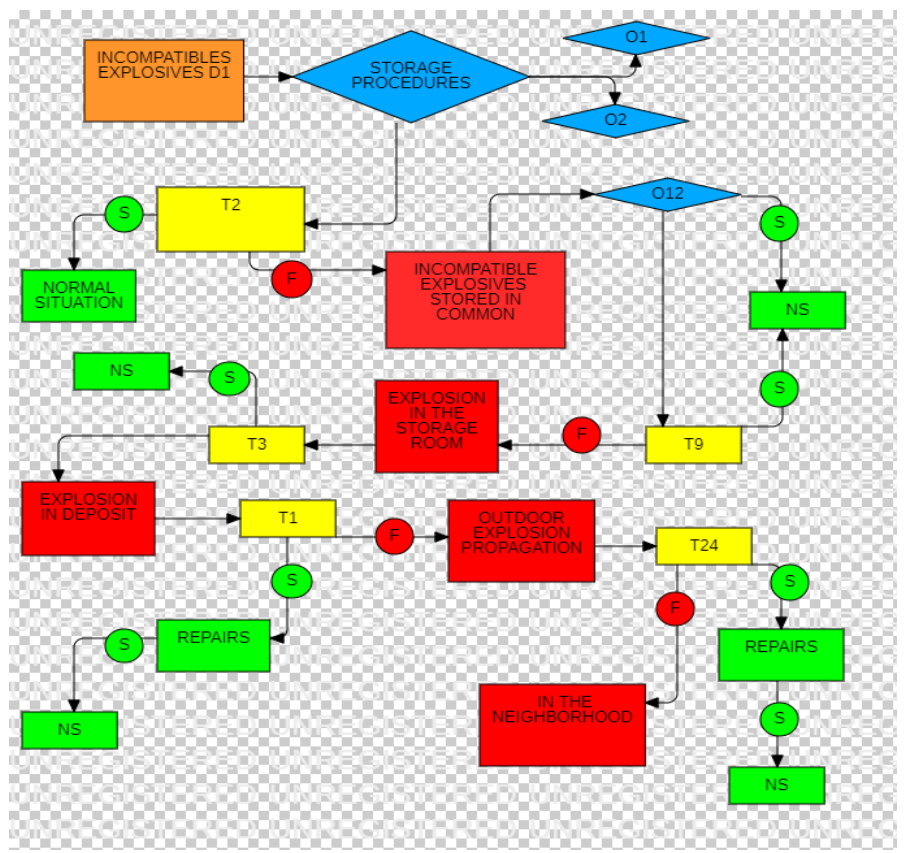

Figure 2.2 - Event tree for trigger factor D1 - Incompatible explosives

where $\boldsymbol{O 1}$ - Procedures for avoiding the joint storage of incompatible explosives; 02 - Procedures for Labeling Explosives by Compatibility Groups; T2 - Arranging separate rooms for storing incompatible explosives; O12 Procedures for adapting the explosives storage flow to shorten storage times; T9 - Explosive distribution flow adapted to reduce storage time; T3-Concrete protection barriers between the storage rooms; $\mathbf{T} 1$ - Constructive protection of the warehouse (building) - type of warehouse; T24 - Barricades, fences, earth waves for the protection of the deposit

Table 2.3- Accident sequence table for trigger factor D1 - Incompatible explosives

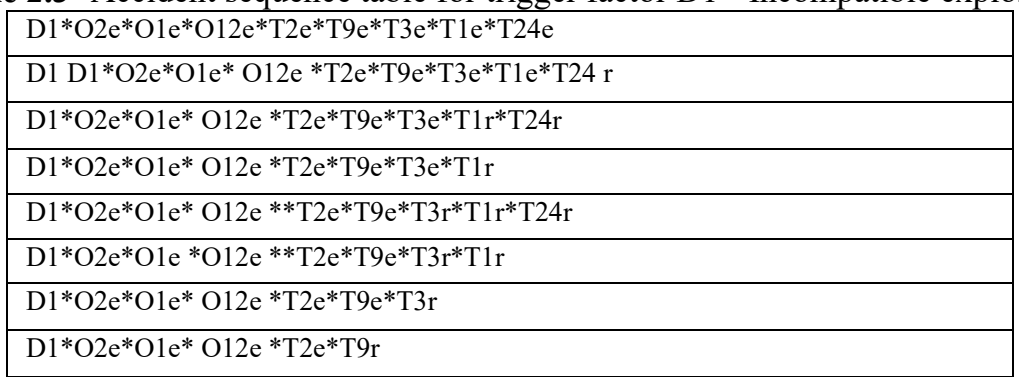




\begin{tabular}{|l|}
\hline $\mathrm{D} 1 * \mathrm{O} 2 \mathrm{e}^{*} \mathrm{O} 1 \mathrm{e}^{*} \mathrm{O} 12 \mathrm{e} * \mathrm{~T} 2 \mathrm{r} * \mathrm{~T} 9 \mathrm{r}$ \\
\hline $\mathrm{D} 1 * \mathrm{O} 2 \mathrm{e}^{*} \mathrm{O} 1 \mathrm{e}^{*} \mathrm{~T} 2 \mathrm{r}$ \\
\hline $\mathrm{D} 1 * \mathrm{O} 2 \mathrm{r}^{*} \mathrm{O} 1 \mathrm{r} * \mathrm{~T} 2 \mathrm{r}$ \\
\hline
\end{tabular}

In order to perform the explosion risk analysis in the industrial explosive storage sites, a logical scheme was developed, based on the comparison between the analyzed site and a hypothetical complete site, in which it is considered that all safety measures have been successfully planned and implemented. scheme being presented in Figure 2.3.

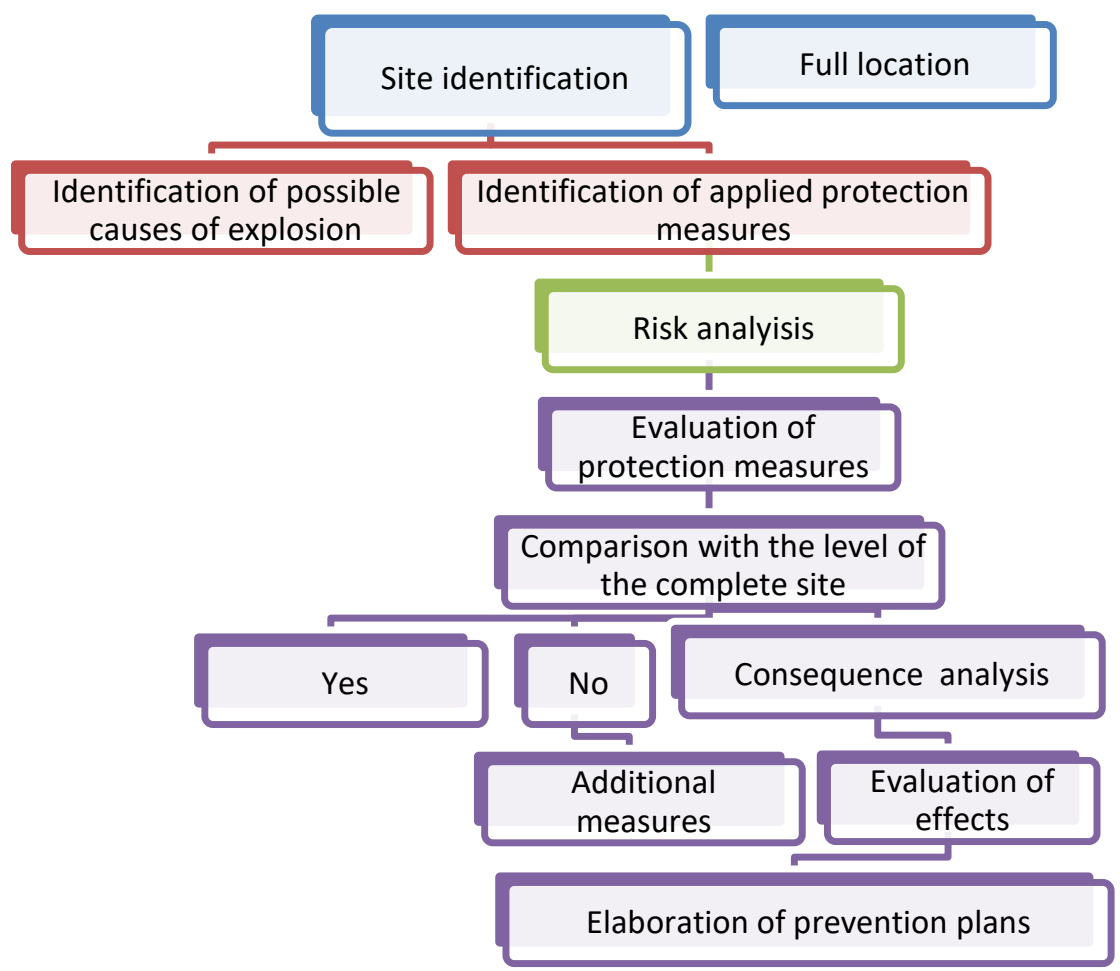

Figure 2.3. - Logical diagram of analysis of a storage location

\section{Design of computer application specific to explosion risk management in explosives depots}

\subsection{Purpose and utility}

The use of a computer application in the field of explosion risk management at explosives depots for civil use allows to ensure the necessary premises for the elaboration, in objective and specific conditions, of the necessary documents for these types of technical 
infrastructures, from their design phase and quantification of damage to the analyzed locations but also to the areas that are located in their vicinity. The IT application is a viable solution to solve the problems in the field of major risks specific to technical infrastructure for storage of explosives, which can help perform a quick analysis of the site, to impose conditions prior to construction of the objective in its design phase.

The benefits that can be estimated are the following:

- Safer working and living conditions, as well as environmental sustainability, achieved following the decrease of the possibilities of an explosion

- The results provided by the application can bring important and real benefits to economic operators that have technical infrastructure for the storage of explosives for civilian use.

- Providing information support to the competent authorities with responsibilities in the authorization and verification of explosives depots, but also to persons designated by economic operators active in the field for a quick and concrete verification of a storage site.

In fact, the use of this application allows a fairly quick analysis of a storage location, the concrete identification in the field of the possibilities of possible triggers, the identification of the type of prevention and / or limitation measures to be applied, in finally providing a concrete image of the areas of influence in which a possible explosion manifests its effects. Based on this analysis, operators in the field can complete, modify or adapt prevention policies, safety plans, safety documentation and, in general, the entire explosion risk management process specific to an explosives storage site.

\subsection{Principles of computer application design}

In order to develop a computer application that can help the user in the process of explosion risk management specific to explosives depots, the following principles have been established, which were later included in the working stages of the application.

1. Identifying the possible triggers of an explosion;

2. Identification of organizational measures that can be applied at the level of an explosives depot;

3. Identification of technical measures that can be applied at the level of an explosives depot;

4. Identification and elaboration of sequences of specific events for each of the triggered factors analyzed, in association with the safety measures that can be applied;

5. Elaboration of event trees for each of the triggered factors analyzed;

6. Identification and delimitation of protection areas, emergency planning areas according to the amount of explosives stored, corresponding to each warehouse analyzed, an absolutely mandatory tool in the risk management process related to explosives depots.

In order to delimit the stages of this application, the following logic scheme was elaborated,which includes the application steps, presented in Figure 3.1. 


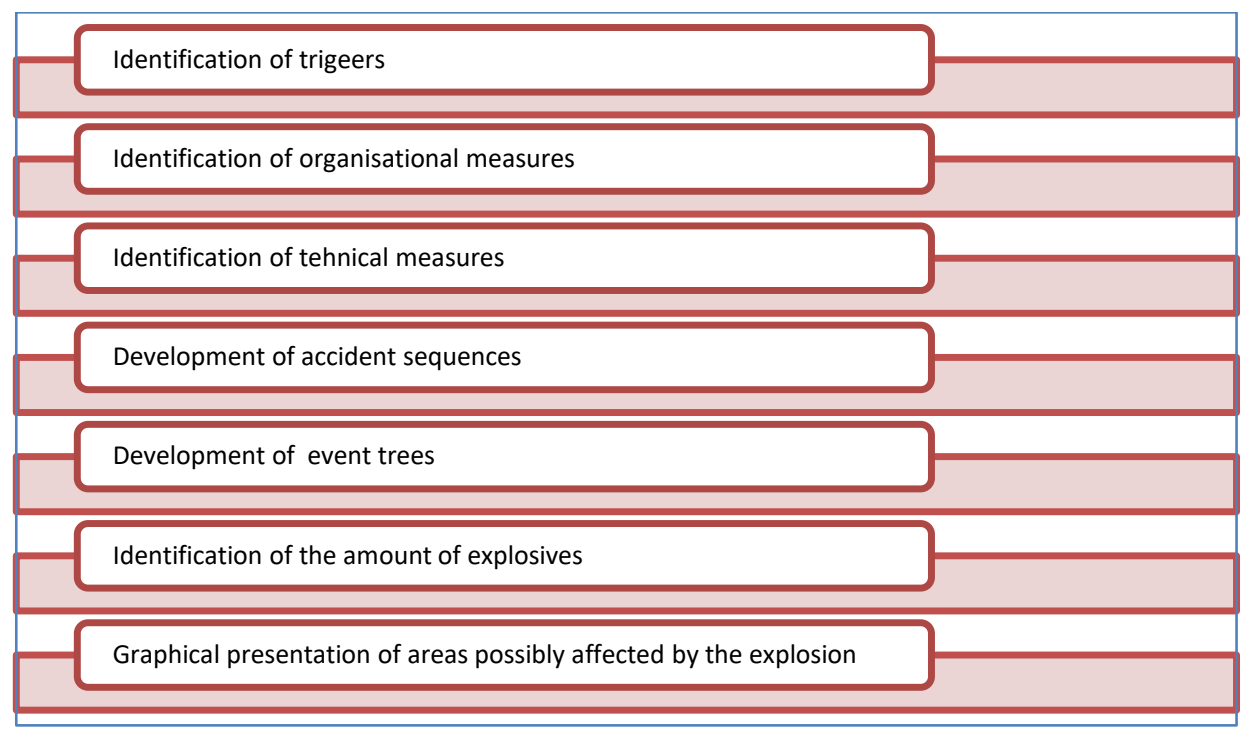

Figure 3.1. - Logic scheme used to develop the application

\subsection{Working steps of the application}

\section{Stage 1 - Home page}

It will include three components that delimit the working stages of the application, START, ACCIDENT SEQUENCES and PROTECTION AREAS

\section{Stage 2 - Accident sequences}

Step 1 - Open by clicking the Accident Sequences ;

Step 2 - In this stage, the first check-list is completed to identify the triggers, with Yes / No boxes corresponding to each factor, which are filled in according to the trigger factor (s) that will be analyzed;

Step 3- In this stage, a checklist is filled in to identify the organizational measures, with Yes / No boxes corresponding to each measure, which are filled in depending on its presence or absence. After completing the checklist, move on to the next step;

Step 4- In this stage, a check-list is completed to identify the technical measures, with Yes / No boxes corresponding to each measure, which are completed depending on its presence or absence. After completing the checklist, move on to the next step;

Step 5- After completing the previous checklists, depending on the triggers, the organizational and technical measures identified or not and completed in the application, the screen generates the name of the factor / factors completed in the application, the accident sequences and the corresponding event tree. If the appropriate safety measures have been implemented for the analyzed triggers and completed in the previous steps of the application, the accident sequences are marked in green, and the absence of one or more of the measures provided by the accident sequence leads to its marking red color.

\section{Stage 3 - Determination of protection zones according to the amount of explosives}

This stage of the application allows the analysis and delimitation of protection zones, an absolutely necessary tool for emergency management, so that, taking into account the most negative scenario possible, ie the explosion of the entire amount of explosive, equivalent to $\mathrm{TNT}$, stored in the analyzed location, all necessary measures are provided to limit the 
effects of a possible explosion on the neighborhoods, including primarily human communities and the environment.

The stage opens from the corresponding box on the home page

Step 1 - A box appears on the screen in which the quantity of explosives in TNT equivalent from the analyzed location is filled in numerically, stored in one or more storage rooms or in the entire warehouse;

Step 2-Depending on the amount of explosive completed in the previous step, the protection areas required for emergency planning activities appear on the screen, indicating the safety distances around the deposits corresponding to each area.;

\section{Conclusions}

This paper established the criteria for developing a specialized computer application that can be an analysis tool from the design phase of a warehouse, but also a tool that can be used to quickly identify existing risks on a site and security measures that can / should be implemented. The results highlighted in the paper are addressed to those involved in the explosion risk assessment specific to industrial sites for the storage of explosive materials, to establish the necessary prevention and protection measures to eliminate, limit and combat risk factors that may cause undesirable events. serious / devastating consequences and the use of safe practices to ensure the highest possible level of security.

The paper presents the procedural ways to configure the main danger scenarios generated in specific explosive activities, providing a technical solution for computer modeling of the risk of explosion, so as to achieve efficient site management and safety of communities and civil / industrial targets in the vicinity.

\section{References}

1. Cekerevac D, C. Rigueiro C, Pereira E - Characterization of accidental scenarios for offshore structures, Ce/Papers,vol. 1, no. 2-3, pp. 4341-4350, 2017

2. Vasilescu G.V, Burdea F.,Vedinaș F., StoianF., Vasilescu G. D. -Analysis of the specific dangerous scenarious for industrial site of the field of explosives for civil uses -19th International Multidisciplinary Scientific Geoconference SGEM 2019 Conference Proceedings Vol. 19 Science and Technologies in Geology, Exploration and Mining ISSUE 1.3, pag.47- 56 ISBN 978-619-7408-78-2 28 June - 7 July Albena Resort \& Spa, Bulgaria

3. Burdea F., Burdea C, Vasilescu V., Anghelache D., Vasilescu G - Development of risk assessment methodological basis for establishments concerned by the requirements of SEVESO II Directive.- 18th International Multidisciplinary Scientific GeoConference SGEM 2018,2 - 8 July, 2018 ,Albena Resort, Bulgaria Vol. 18, ISSUE 1.3, ISBN 978-6197408-37-9 ISSN 1314-2704 Pag. 303 $\div 310$

4. Cioca, L.I., Moraru, R., Băbuţ, G. - Occupational Risk Assessment: A Framework for Understanding and Practical Guiding the Process in Romania, Proceedings of the International Conference on RISK MANAGEMENT, ASSESSMENT and MITIGATION (RIMA '10), pp. 56-61, Bucharest, Romania, 20-22.04.2010, WSEAS Press, 2010; ISSN: 1790-2769, ISBN: 978-960-474-182-3

5. Burdea F.I., Moraru, R.I - Event-based Analysis of Accidentogenic Scenarios for Explosive Deposits Annals of the University of Petroşani, Mining Engineering, 21 (2020), p.50-61, ISSN 1454-9174,, vol. 21 (XLVIII), Universitas Publishing House Petroşani Romania 2020 
6. Papazoglou, I.A., Saravanos, P., Giakoumatos, I., Aneziris, O.N.,- Quantified risk assessment for plants producing and storing explosives. In: Kolowrocki, K., (Ed.), Proceedings of the ESREL 2005, Advances in Safety and Reliability. Taylor \& Francis Group, London, UK, 2005.

7. Papazoglou, I.A, Aneziris, O., Konstandinidou, M., Giakoumatos,I.,--Accident sequence analysis for sites producing and storing explosives, Accident Analysis and Prevention 41 (2009) 1145-1154.

8. HSE - Manufacture and Storage of Explosives Regulations 2005. UK.

9. Moraru, R.- Current Trends and Future Developments in Occupational Health and Safety Risk Management în Roland Iosif Moraru (2012). Current Trends and Future Developments in Occupational Health and Safety Risk Management, Risk Management for the Future - Theory and Cases, Dr Jan Emblemsvåg (Ed.), , InTech, DOI: 10.5772/1809.

10. CEI/IEC - Analyse par arbre de panne (AAP), CEI 1025:1990. 